\title{
Imiquimod 5\% as Adjuvant Therapy for Incompletely Excised Infiltrative Nodular Basal Cell Carcinoma and Dermoscopy to Monitor Treatment Response
}

\author{
Rodrigo Roldán-Marín (ID · Sonia Toussaint-Caire
}

To view enhanced content go to www.dermtherapy-open.com

Received: September 30, 2015 / Published online: November 4, 2015

(C) The Author(s) 2015. This article is published with open access at Springerlink.com

\begin{abstract}
Introduction: A relatively novel application for dermoscopy is its use in the monitoring of topical treatment response for non-melanoma skin cancer. Basal cell carcinoma (BCC) is the most frequent type of skin cancer in humans. Surgical excision is still considered the "gold-standard" of treatment. However, a number of topical therapies are now available for the treatment of different types of basal cell carcinoma.
\end{abstract}

Case Report: This case report exemplifies the usefulness of dermoscopy in the monitoring of residual disease after incomplete surgical excision and also in the monitoring of topical treatment response. Imiquimod 5\% cream acts as a topical immune response modifier

Electronic supplementary material The online version of this article (doi:10.1007/s13555-015-0088-z) contains supplementary material, which is available to authorized users.

R. Roldán-Marín ( $\square)$

Faculty of Medicine, Universidad Nacional

Autónoma de México, Mexico City, Mexico

e-mail: roroderm@yahoo.com

S. Toussaint-Caire

Dermatology Department, Hospital General Dr.

Manuel Gea González, Mexico City, Mexico promoting a Th-1 immune response enhancing the removal of neoplastic cells and has proven to reduce deregulated Hedgehog $(\mathrm{HH}) / \mathrm{GLI}$ signal strength independent of Toll-like receptor signaling, which makes it a valuable adjuvant topical therapy for the treatment of basal cell carcinoma.

Conclusion: Imiquimod 5\% cream is a valuable adjuvant therapy for the treatment of incompletely excised BCC. This case report adds further evidence to the usefulness of dermoscopy in the assessment and monitoring of treatment outcome.

Keywords: Adjuvant; Basal cell; Carcinoma; Dermoscopy; Imiquimod

\section{INTRODUCTION}

Dermoscopy is a valuable noninvasive technique that increases diagnostic accuracy in melanoma and non-melanoma skin cancer [1, 2]. Recently, its use as an aid in the monitoring of topical treatment response has also been described [2-4]. Basal cell carcinoma (BCC) is the most frequent type of skin cancer in humans. Surgical excision is still considered 
the "gold-standard" of treatment. However, a number of topical therapies are now available for the treatment of different types of basal cell carcinoma. Despite the fact that BCC is associated with a low mortality and very rarely gives rise to metastatic disease, delays in its correct diagnosis and treatment prolong patient morbidity and increase the cost of care. Dermoscopy has also shown to be useful in the assessment of early recurrence or tumor persistence. Dermoscopic criteria such as pigmented structures, ulceration and arborizing vessels have been suggested to predict the presence of residual disease (residual disease-associated dermoscopic criteria) [4, 5].

This case report exemplifies the usefulness of dermoscopy in the assessment of residual disease after incomplete surgical excision and also in the monitoring of topical treatment response.

\section{CASE REPORT}

An otherwise healthy, 92-year-old woman was seen for the evaluation and treatment of a "long-standing" nodular lesion on the tip of her nose. The lesion was characterized as a solitary, $5 \mathrm{~mm}$, smooth, nodular, pearly tumor with telangiectasia (Fig. 1). Dermoscopy confirmed the diagnosis of nodular BCC because of the presence of telangiectasia and arborizing vessels (Fig. 2). The patient was completely asymptomatic. Surgical excision with $5 \mathrm{~mm}$ safety margins was performed. The wound healed by secondary intention with daily topical application of a pirfenidone gel (Fig. 3) (Kitoscell-Q, Cell Therapy and Technology, S.A. de C.V., Mexico). Histopathologic examination revealed a neoformation arising from the epidermis proliferating into the papillary and

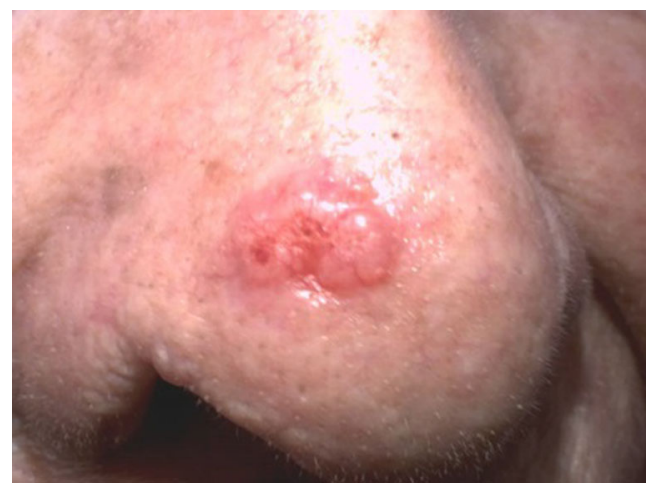

Fig. 1 The lesion on the nose was characterized as a solitary, $5 \mathrm{~mm}$, smooth, nodular, pearly tumor with telangiectasia

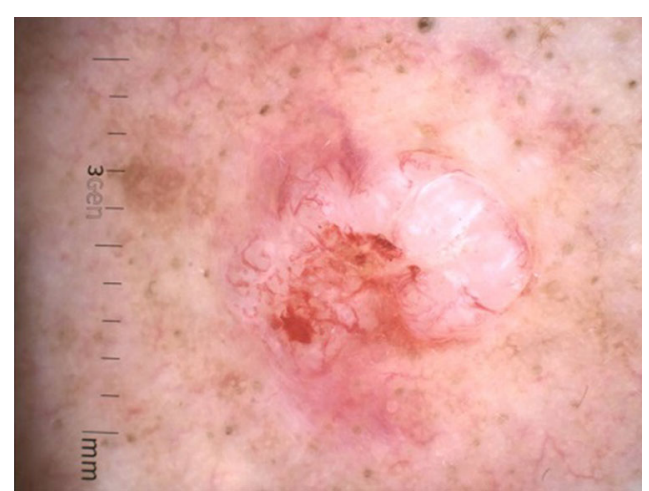

Fig. 2 Dermoscopy confirmed the diagnosis of nodular basal cell carcinoma because of the presence of telangiectasia and arborizing vessels

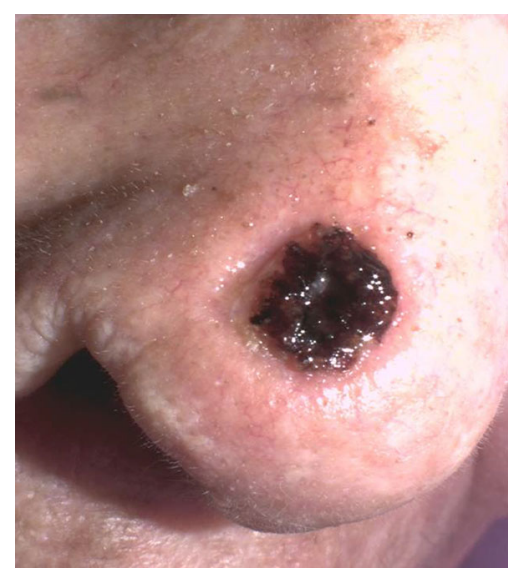

Fig. 3 Wound healed by secondary intention with daily topical application of a pirfenidone gel 
a
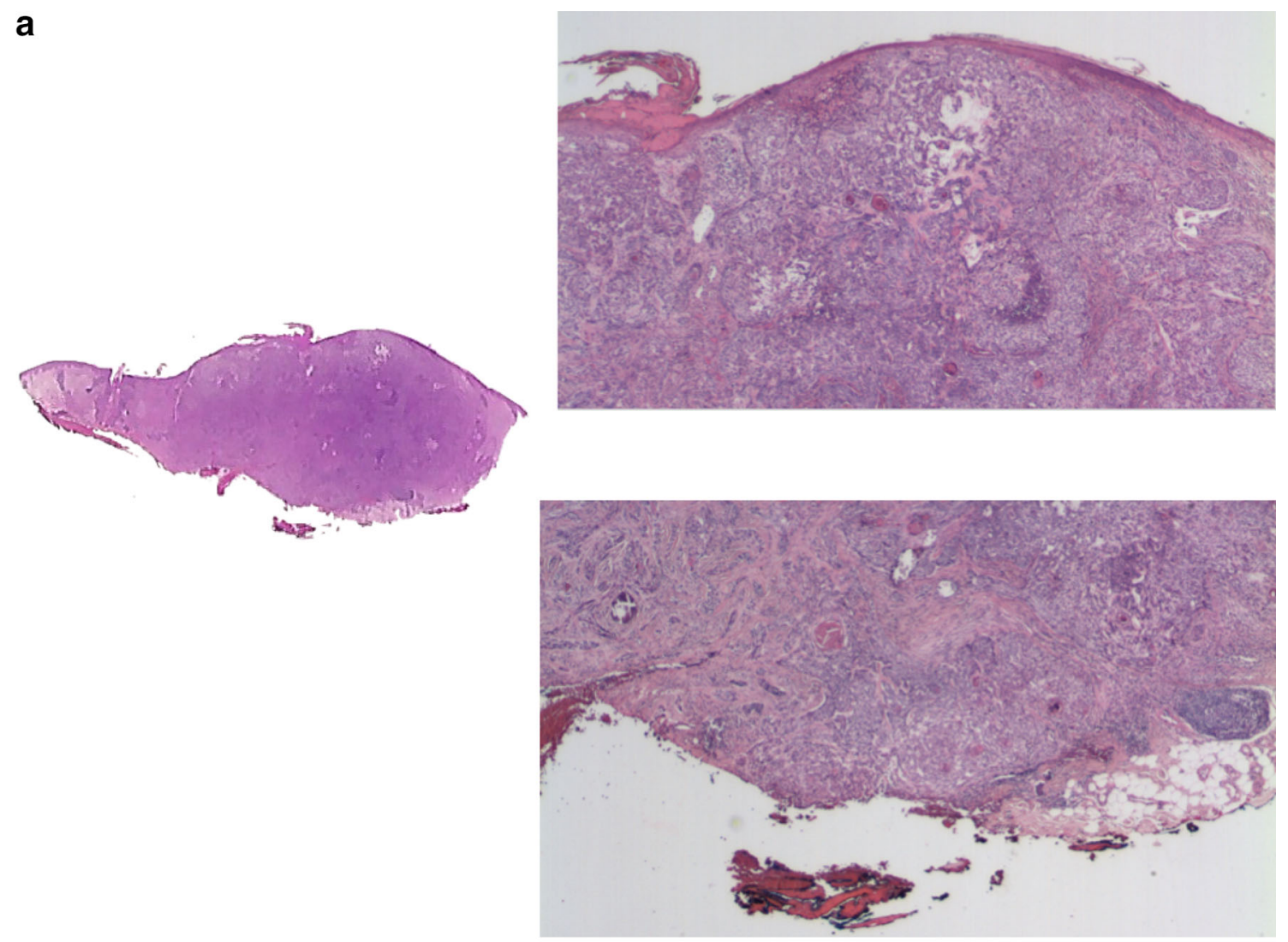

b

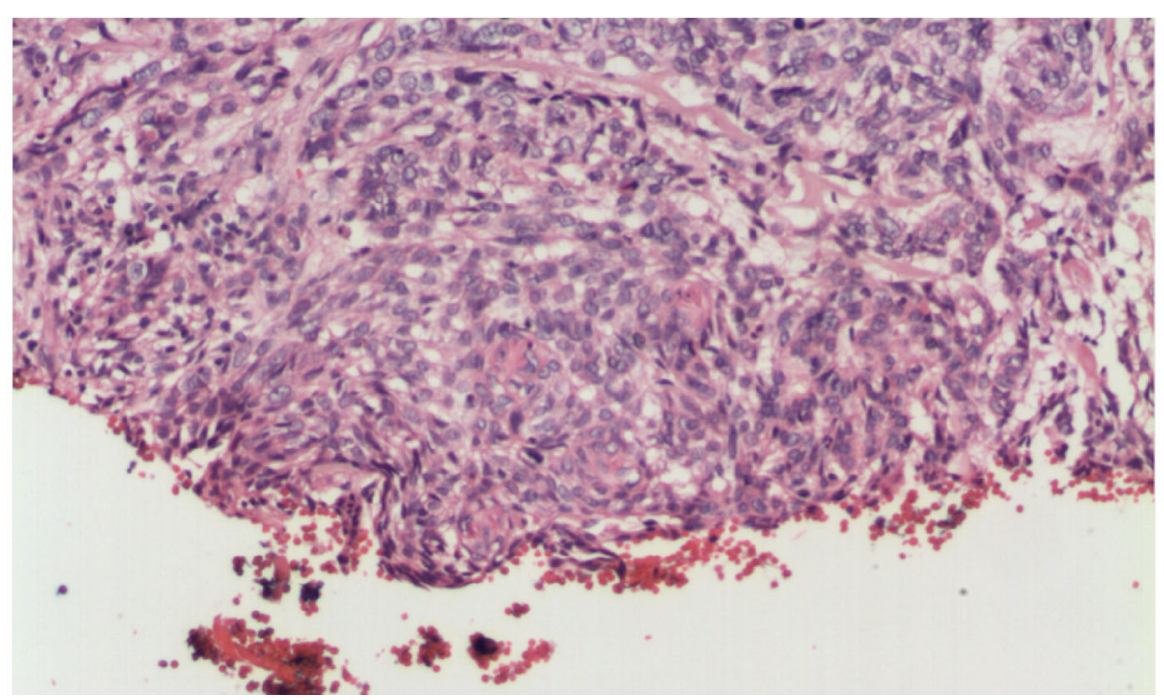

Fig. 4 a $(\times 10, \times 20)$ and $\mathbf{b}(\times 40)$. Histology confirmed the diagnosis of infiltrating nodular basal cell carcinoma and remains of tumoral cells within the wound bed and deep margins

reticular dermis. It was constituted by an epithelial tumor with basaloid-appearing cells disposed in palisade at the periphery of the tumor nests. The neoplastic cells had large hyperchromatic nuclei with mitosis and individual cellular necrosis. The tumoral nests were surrounded by a lymphocytic inflammatory infiltrate and a fibromyxoid stroma with stromal 
retraction artifact in certain areas. The tumor extended into the deep margins where tumoral nests were smaller, with angular shapes and interspersed by a more fibrous stroma. Histology confirmed the diagnosis of infiltrating nodular BCC and remains of tumoral cells within the wound bed and deep margins (Fig. 4). Six weeks after the incomplete surgical excision, the esthetic result was acceptable (Fig. 5). However, dermoscopy confirmed the persistence of the tumor characterized by a large arborizing vessel (Fig. 6). The patient and her family members denied a second surgical intervention and/or radiotherapy. For this reason and due to the ease of at-home application, daily topical treatment with $5 \%$ imiquimod cream for 8 weeks was started (Fig. 7). Follow-up was performed every 3 weeks. Clinically and dermoscopically the patient revealed an appropriate response to the topical treatment characterized mainly by erythema and mild ulceration (Fig. 8). Four weeks after the end of treatment, the clinical esthetic result was acceptable (Fig. 9). At 12 months after the end of treatment dermoscopy confirmed the absence of any signs of recurrence (Fig. 10). The patient was last seen

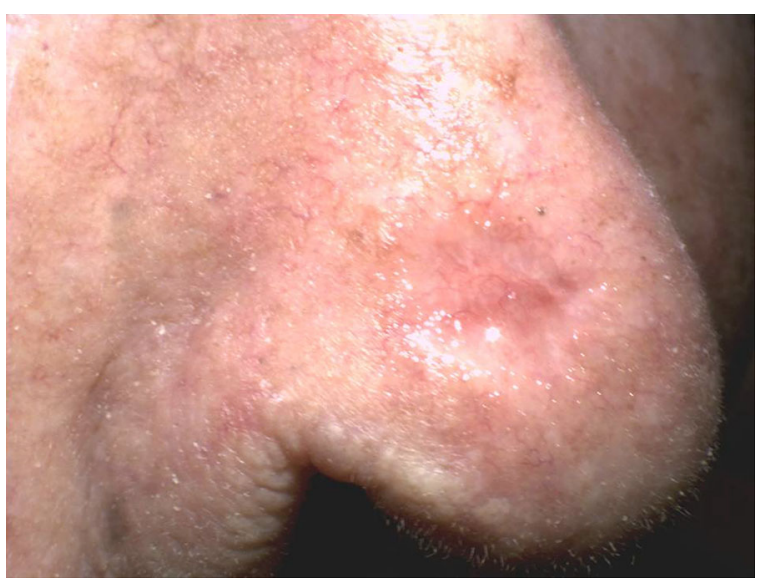

Fig. 5 Six weeks after the incomplete surgical excision the esthetic result was acceptable

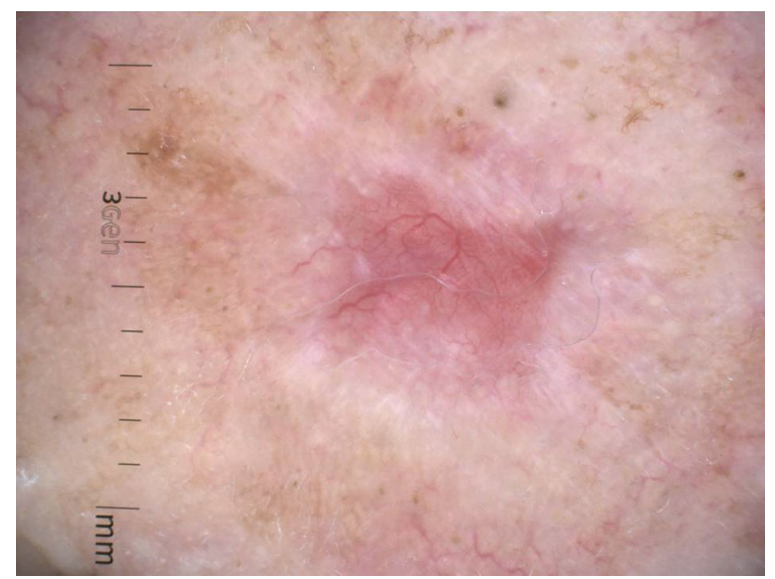

Fig. 6 Dermoscopy confirmed the persistence of the tumor characterized by a large arborizing vessel
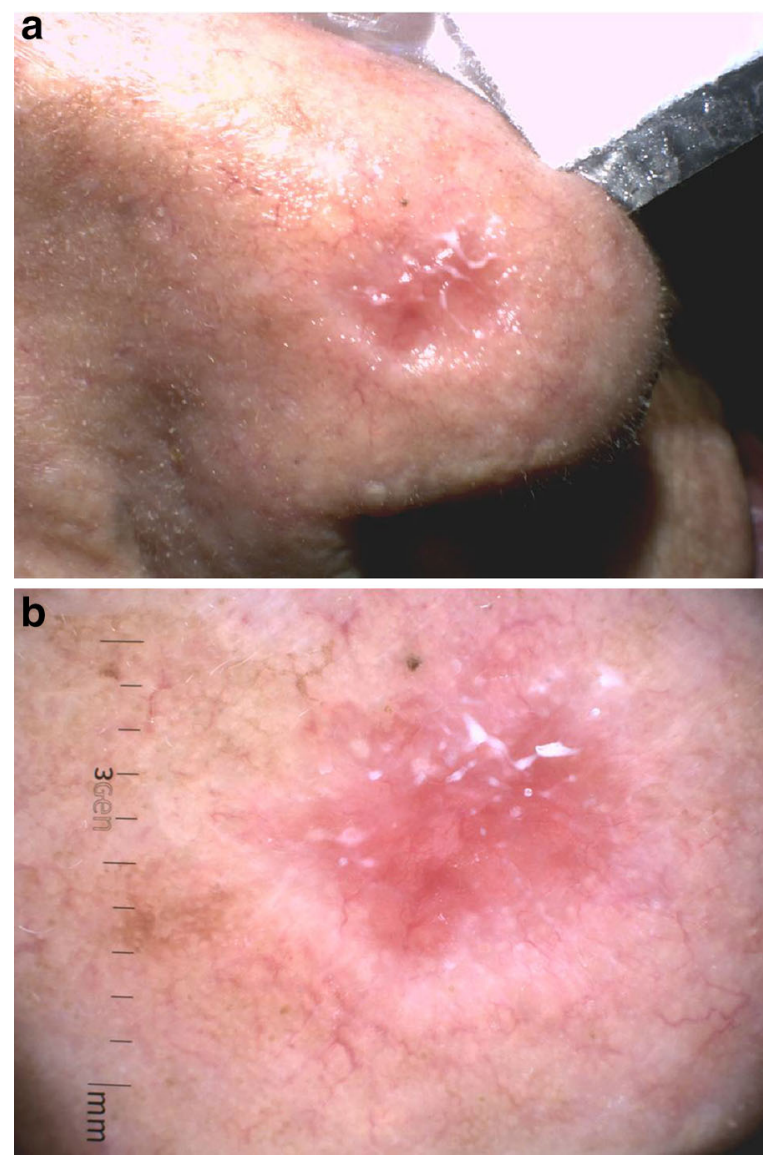

Fig. 7 a, b Daily topical treatment with 5\% imiquimod cream was started 

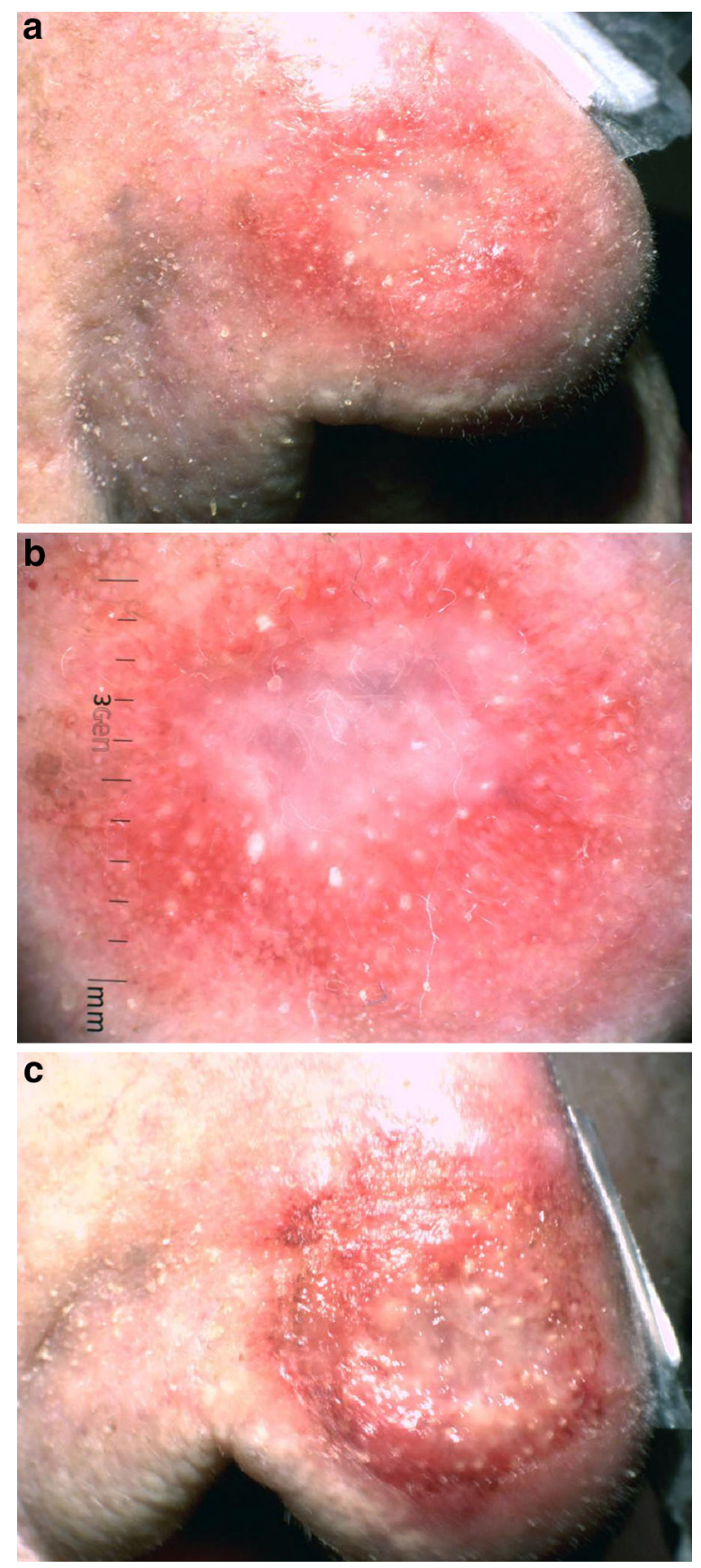

Fig. 8 a-f Clinically and dermoscopically the patient revealed an appropriate response to the topical treatment characterized mainly by erythema and mild ulceration

23 months after the end of treatment without any signs of recurrence and dermoscopy confirmed the eradication residual disease (Fig. 11). All procedures followed were in
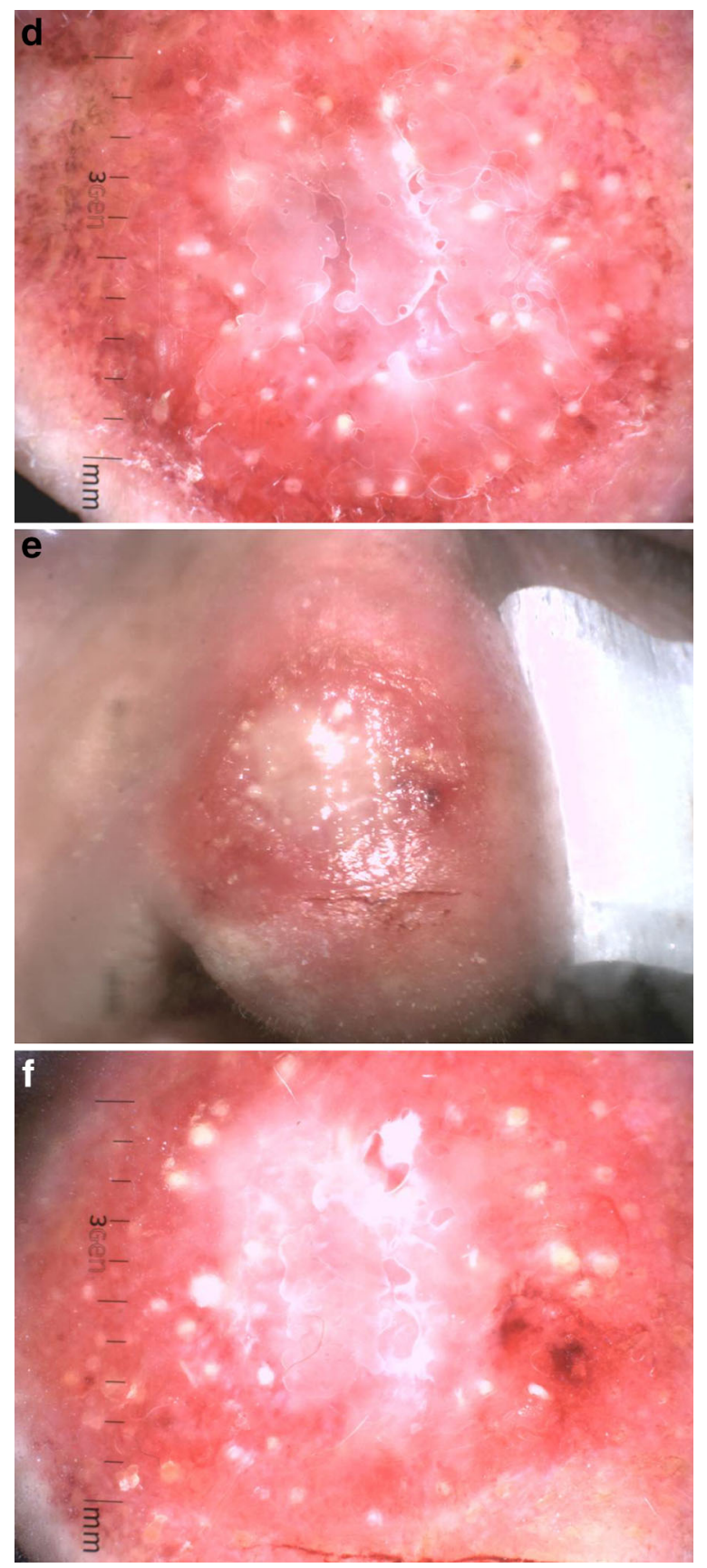

Fig. 8 continued

accordance with the ethical standards of the responsible committee on human experimentation (institutional and national) and with the Helsinki Declaration of 1964, as revised in 2013. Informed consent was obtained from all patients for being included in the study. 


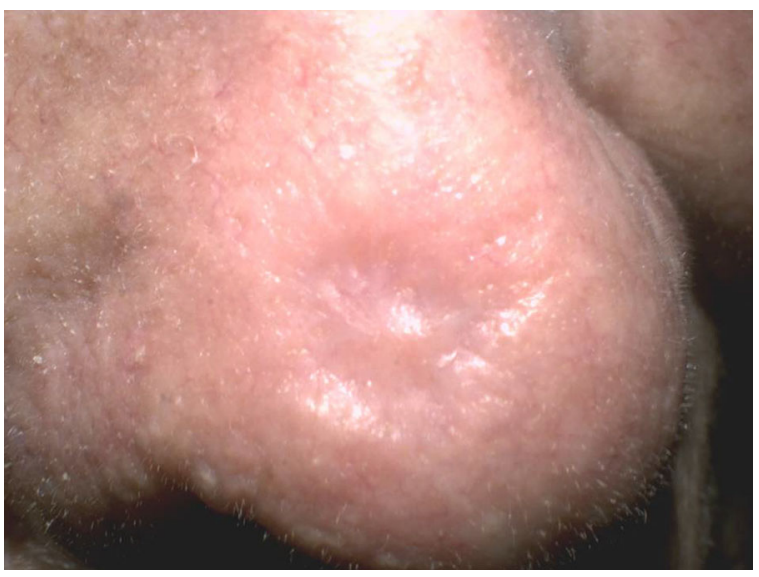

Fig. 9 Four weeks after the end of 5\% imiquimod treatment the clinical esthetic result was acceptable

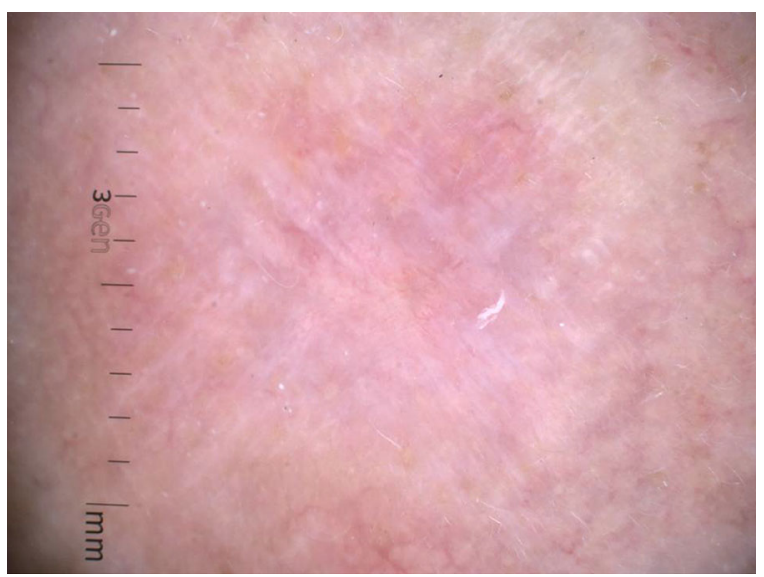

Fig. 10 One year later the patient had no signs of recurrence confirmed by dermoscopy

\section{DISCUSSION}

Basal cell carcinoma is the most frequent cancer of the skin and its incidence is increasing worldwide [4]. Surgery, including Mohs micrographic surgery, is considered the "gold standard" of treatment and the most effective in terms of recurrence rates. Rates of incomplete excision of BCC range from $4 \%$ to $16.6 \%$ [6]. Incomplete excision has been associated with various recurrence rates ranging from $26 \%$ to $67 \%$ and $50 \%$ of recurrences occur within the next 6-12 months [6]. Certain anatomic locations
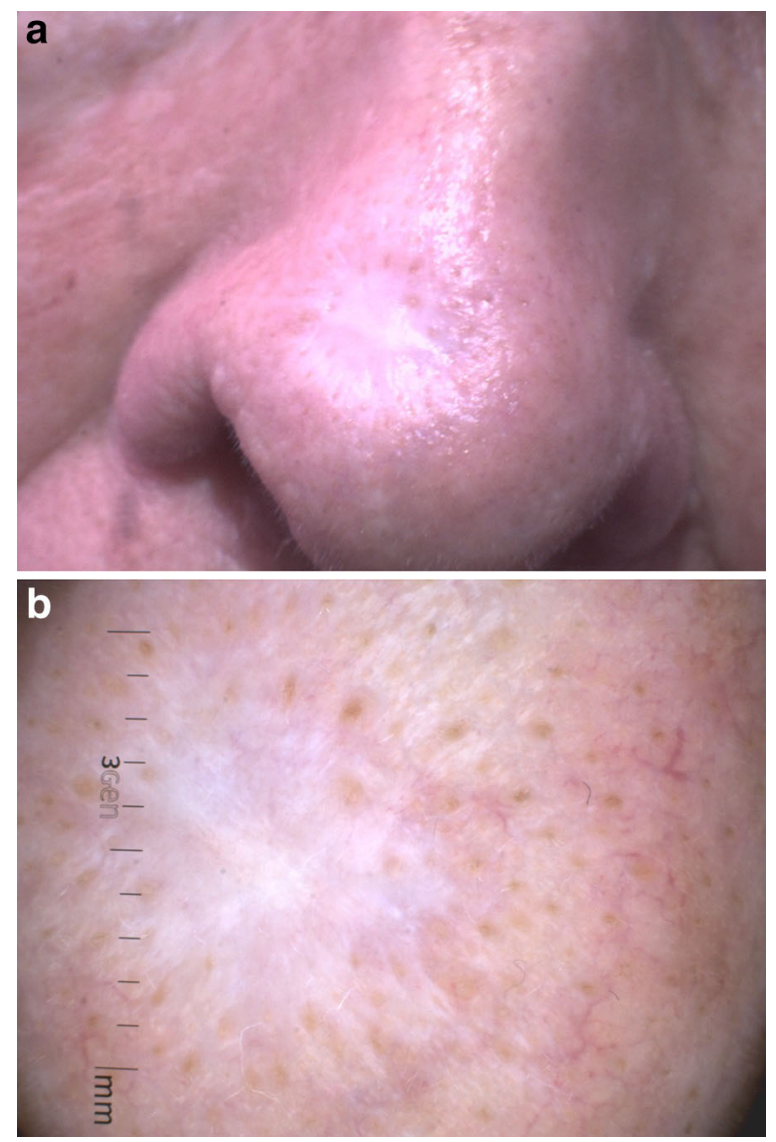

Fig. 11 Clinical and dermoscopic appearance 23 months after the end of treatment. Dermoscopy shows no signs of tumor recurrence and confirms eradication of residual disease

such as the nose and inner canthus, as well as certain histologic subtypes such as infiltrative and multifocal, have been associated as predictive factors for incomplete excision [6]. In cases where the surgical intervention is unable to completely remove the tumor, adjuvant therapy such as a second surgical procedure, radiotherapy, photodynamic therapy and topical immunotherapy are used [7]. Imiquimod is a Toll-like receptor-7/8 (TLR-7/8) agonist that acts as a topical immune response modifier and has been reported as a non-surgical alternative for the treatment of BCC, particularly for the superficial subtype [7, 8]. Topical imiquimod 5\% cream promotes a Th-1 immune response aimed at 
enhancing the removal of neoplastic cells. Recently, imiquimod 5\% cream has been described as a novel alternative to reduce deregulated Hedgehog (HH)/GLI signal, independent of TLR signaling. Small molecule targeting of $\mathrm{HH}$ signaling by inhibiting the essential pathway effector smoothened has proven exceptionally efficient for the treatment of advanced and metastatic basal cell carcinoma. However, severe side effects, limited response rates, and rapid development of drug resistance may limit the therapeutic success of SMO antagonists. This reflects the need for the identification of alternative and additional strategies repressing oncogenic HH signaling [9]. Imiquimod 5\% may be one of such alternatives as a topical, safe and relatively easy to use drug for the treatment of different BCC subtypes as adjuvant or neoadjuvant therapy [10].

\section{CONCLUSION}

Our case report exemplifies that dermoscopy is a valuable diagnostic aid that also serves to assess tumor recurrence/residual disease and to monitor topical treatment response. It also adds further evidence to the use of imiquimod as an important topical neoadjuvant or adjuvant therapy for the treatment of BCC and residual disease in cases with incomplete surgical excision $[10,11]$.

\section{ACKNOWLEDGMENTS}

No funding or sponsorship was received for this study or publication of this article.

All named authors meet the International Committee of Medical Journal Editors (ICMJE) criteria for authorship for this manuscript, take responsibility for the integrity of the work as a whole, and have given final approval for the version to be published.
Disclosures. R. Roldán-Marín and S. Toussaint-Caire have nothing to disclose.

Compliance with ethics guidelines. All procedures followed were in accordance with the ethical standards of the responsible committee on human experimentation (institutional and national) and with the Helsinki Declaration of 1964, as revised in 2013. Informed consent was obtained from all patients for being included in the study.

Open Access. This article is distributed under the terms of the Creative Commons AttributionNonCommercial 4.0 International License (http://creativecommons.org/licenses/by-nc/4. $0 /$ ), which permits any noncommercial use, distribution, and reproduction in any medium, provided you give appropriate credit to the original author(s) and the source, provide a link to the Creative Commons license, and indicate if changes were made.

\section{REFERENCES}

1. Vestergaard ME, Macaskill P, Holt PE, Menzies SW. Dermoscopy compared with naked eye examination for the diagnosis of primary melanoma: a meta-analysis of studies performed in a clinical setting. $\mathrm{Br} \mathrm{J}$ Dermatol. 2008;159:669-76.

2. Lallas A, Argenziano G, Zendri E, Moscarella E, Longo C, Grenzi L, Pellacani G, Zalaudek I. Update on non-melanoma skin cancer and the value of dermoscopy in its diagnosis and treatment monitoring. Expert Rev Anticancer Ther. 2013;13:541-58.

3. Zalaudek I, Lallas A, Moscarella E, Longo C, Soyer HP, Argenziano G. The dermatologist's stethoscope-traditional and new applications of dermoscopy. Dermatol Pract Concept. 2013;3:67-71.

4. Apalla Z, Lallas A, Tzellos T, Sidiropoulos T, Lefaki I, Trakatelli M, Sotiriou E, Lazaridou E, Evangelou G, Patsatsi A, Kyrgidis A, Stratigos A, Zalaudek I, Argenziano G, Ioannides D. Applicability of 
dermoscopy for evaluation of patients' response to nonablative therapies for the treatment of superficial basal cell carcinoma. $\mathrm{Br} \mathrm{J}$ Dermatol. 2014;170:809-15.

5. Cuellar F, Vilalta A, Puig S, Palou J, Zaballos P, Malvehy J. Dermoscopy of early recurrent basal cell carcinoma. Arch Dermatol. 2008;144:1254.

6. Farhi D, Dupin N, Palangié A, Carlotti A, Avril MF. Incomplete excision of basal cell carcinoma: rate and associated factors among 362 consecutive cases. Dermatol Surg. 2007;33:1207-14.

7. Thissen MR, Kuijpers DI, Krekels GA. Local immune modulator (imiquimod 5\% cream) as adjuvant treatment after incomplete Mohs micrographic surgery for large, mixed type basal cell carcinoma: a report of 3 cases. J Drugs Dermatol. 2006;5:461-4.

8. Bath-Hextall F, Ozolins M, Armstrong SJ, Colver GB, Perkins W, Miller PS, Williams HC. Surgery versus imiquimod for nodular superficial basal cell carcinoma (SINS) study group. Surgical excision versus imiquimod $5 \%$ cream for nodular and superficial basal-cell carcinoma (SINS): a multicentre, non-inferiority, randomised controlled trial. Lancet Oncol. 2014;15:96-105.

9. Gruber W, Frischauf AM, Aberger F. An old friend with new skills: imiquimod as novel inhibitor of Hedgehog signaling in basal cell carcinoma. Oncoscience. 2014;1:567-73.

10. Kaçar SD, Özŭguz P, Erkan F, Karaca Ş. Treatment of various types of basal cell carcinoma with topical $5 \%$ imiquimod in the elderly who refused surgical intervention: a case series. J Dermatolog Treat. 2015;26:165-7.

11. de Macedo EM, Carneiro RC, de Lima PP, Silva BG, Matayoshi S. Imiquimod cream efficacy in the treatment of periocular nodular basal cell carcinoma: a non-randomized trial. BMC Ophthalmol. 2015;15:35. doi:10.1186/s12886-0150024-0. 